\title{
CAMA
}

Centre for Applied Macroeconomic Analysis

\section{Endogenous Product Scope: Market Interlacing and Aggregate Business Cycle Dynamics}

\section{CAMA Working Paper 3/2021 January 2021}

\section{Oscar Pavlov}

University of Tasmania

Centre for Applied Macroeconomic Analysis, ANU

\section{Mark Weder}

Aarhus University

Centre for Applied Macroeconomic Analysis, ANU

\section{Abstract}

This paper examines a market interlacing industry configuration in general equilibrium with multi-product firms. In contrast to previous studies which utilize market segmentation, firms produce multiple products even in the complete absence of the love of variety. Product scopes are procyclical and entry and exit of firms generates an endogenous amplification mechanism. When simulated by shocks derived from the efficiency and labor wedges, the model replicates the changes in dynamics between the pre- and post 1983 periods, and explains the hours-productivity puzzle. 


\title{
Keywords
}

Multi-product firms, business cycles

\author{
JEL Classification
}

E32

\section{Address for correspondence:}

(E) cama.admin@anu.edu.au

ISSN 2206-0332

The Centre for Applied Macroeconomic Analysis in the Crawford School of Public Policy has been established to build strong links between professional macroeconomists. It provides a forum for quality macroeconomic research and discussion of policy issues between academia, government and the private sector.

The Crawford School of Public Policy is the Australian National University's public policy school, serving and influencing Australia, Asia and the Pacific through advanced policy research, graduate and executive education, and policy impact. 


\title{
Endogenous Product Scope: Market Interlacing and Aggregate Business Cycle Dynamics*
}

\author{
Oscar Pavlov \\ University of Tasmania \& CAMA \\ Mark Weder ${ }^{\dagger}$ \\ Aarhus University \& CAMA
}

December 21, 2020

\begin{abstract}
This paper examines a market interlacing industry configuration in general equilibrium with multi-product firms. In contrast to previous studies which utilize market segmentation, firms produce multiple products even in the complete absence of the love of variety. Product scopes are procyclical and entry and exit of firms generates an endogenous amplification mechanism. When simulated by shocks derived from the efficiency and labor wedges, the model replicates the changes in dynamics between the pre- and post 1983 periods, and explains the hours-productivity puzzle.

Keywords: Multi-product firms, business cycles.

JEL Classification: E32.
\end{abstract}

*Pavlov and Weder are Research Associates with CAMA. Weder acknowledges research support from the Australian Research Council, under the grant DP140102869.

${ }^{\dagger}$ Department of Economics and Business Economics, Aarhus University, 8210 Aarhus V, Denmark. mweder@econ.au.dk (corresponding author). 


\section{Introduction}

A significant portion of firms are multi-product producers. Bernard et al. (2010) report that close to half of U.S. manufacturing firms produce in multiple 5-digit SIC industries. These firms account for well over 80 percent of total sales. Furthermore, in excess of 90 percent of product creation and destruction occurs within these firms (i.e. as firms adjust their product scopes) as documented by Broda and Weinstein (2010). Additionally, Guo (2019, 2020) presents evidence that the scope of products that firms bring to the market is significantly procyclical. These observations suggest an important role of multi-product firms in shaping the dynamics of aggregate output.

Why do multi-product firms emerge? As emphasized by Bailey and Friedlaender (1982), the firms' existence is enmeshed in realizing cost advantages arising from economies of scope. An alternative motivation, also based on a form of increasing returns to scale, is a love of variety effect coming from, say, a Dixit and Stiglitz (1977) demand system. Along these lines, Feenstra and Ma (2009), Minniti and Turino (2013) and Pavlov and Weder (2017), introduce multi-product firms into a general equilibrium framework and discuss their effects on aggregate economies. What these works share is the specification of the CES aggregator function of goods. All three follow Brander and Eaton's (1984) market segmentation platform in which each nest of goods corresponds to a multi-product firm's output of close substitutes. ${ }^{1}$ That is, the aggregator pulls together varieties from a single firm's goods. While not claiming that our alternative is necessarily a more appropriate case, here we take the market interlacing route in which similar goods from different firms form close substitutes. One of the key takeaways, as we will show, is that under this formulation increasing returns to scale in the aggregation of products in the form of variety effects are no longer required for multi-product firms to exist.

In the market segmentation arrangement, final output is a combination of product nests with each nest consisting of varieties produced by the same firm. Due to the love of variety, the value of this nest to the consumer in terms of an effective consumption basket is higher with the number of different varieties. This form of increasing returns gives firms an incentive to produce multiple products i.e. firms are able to increase their market share by providing more varieties with the resulting revenue being able to cover the costs of developing or marketing the additional product. However, without the love of variety, the consumer does not value product differentiation and introducing new products only leads to a loss of profits. That is, a new product is only going to reduce the market share of the firm's other products and it is then optimal to produce a single product. Pavlov and Weder (2017) show exactly this. Market interlacing packaging, on the other hand, nests different firms' similar goods. A single firm deciding to produce a new product that no other firm is producing obtains all of the market share from the

\footnotetext{
${ }^{1}$ See also Allanson and Montagna (2005).
} 
new product nest. This gives the firm an incentive to introduce it if the extra revenue is able to cover the development costs and some loss of demand for its other products. Since the new product also reduces the demand for other firms' varieties, all firms will have an incentive to compete within the new product nest. Hence, the competition for new market share drives firms to produce multiple goods even in the absence of direct cost benefits or the love of variety.

When considering the implications on aggregate dynamics, market interlacing provides a novel way of generating countercyclical markups, which endogenously amplify the effect of economic shocks. Countercyclical markups in Minitti and Turino (2013) and Pavlov and Weder (2017) arise from their assumptions that firms are large enough to affect the aggregate price index, which is unrelated to the multi-product structure and not required here. Furthermore, product scope variations only affect aggregate dynamics in so far as the intra-firm variety effect exists. The interlacing setup allows to derive endogenous variations of product scope and markups without the love of variety and the aggregate price index effect (see the Supplementary Appendix for more details).

We then frame this setup in dynamic general equilibrium to study the model's ability to explain the U.S. business cycle and product scope dynamics. We extract shocks from the empirical versions of the labor and efficiency wedges and demonstrate that the model matches well the volatilities and correlations of the key macroeconomic variables. Importantly, our model predicts procyclical product scopes of multi-product firms which aligns well with Guo's (2020) findings, the two wedges are able to explain the change in macroeconomic dynamics between the pre-Great Moderation years and the period since 1984 and we can also account for several labor market facts including Christiano and Eichenbaum's (1992) labor-productivity puzzle. ${ }^{2}$

\section{Model}

The economy consists of intermediate sector firms who are able to choose how many distinct goods to produce. These goods are differentiated and hence bring about market power. The commodities are bought by competitive firms that weld them together into the final good that can be consumed or, by adding it to the capital stock, invested. People own the two factors of production and rent out their services on perfectly competitive markets. We begin with setting out the technology side of product aggregation and in particular the market interlacing structure.

\footnotetext{
${ }^{2}$ Of course, this puzzle dates back to Dunlop (1938) and Tarshis (1939).
} 


\subsection{Technology}

Production occurs in two phases. Final goods are produced by perfectly competitive firms as a combination of $N_{t}$ product nests with each nest indexed $j \in\left[0, N_{t}\right]$ being a package of differentiated goods produced by $M_{t}(j)$ intermediate firms. The intermediate inputs are imperfect substitutes and this nature conveys market power to their producers. Let us call each such good $y_{t}(j, i)$ where $j$ denotes the product supplied and $i$ the firm. The composite of each of these goods (i.e. a nest), coming from the different producers, is

$$
Y_{t}(j)=M_{t}(j)^{\frac{1}{1-\theta}}\left(\int_{0}^{M_{t}(j)} y_{t}(j, i)^{\frac{\theta-1}{\theta}} d i\right)^{\frac{\theta}{\theta-1}} \quad \theta>1 .
$$

Each of these composites is then collected to make up final output as in

$$
Y_{t}=N_{t}^{\frac{1}{1-\gamma}}\left(\int_{0}^{N_{t}} Y_{t}(j)^{\frac{\gamma-1}{\gamma}} d j\right)^{\frac{\gamma}{\gamma-1}} \quad \gamma>1 .
$$

In the following, we will call $\theta$ the inter-firm and $\gamma$ the inter-product elasticities of substitution. The substitutability across the same products is higher than the substitutability across different products or $\theta>\gamma$ and we impose that CES-aggregators eliminate any love-of-variety effects. ${ }^{3}$ Demand for good $y_{t}(j, i)$ is

$$
y_{t}(j, i)=\left(\frac{p_{t}(j, i)}{P_{t}(j)}\right)^{-\theta}\left(\frac{P_{t}(j)}{P_{t}}\right)^{-\gamma} \frac{Y_{t}}{M_{t}(j) N_{t}}
$$

given the price index for product $j$

$$
P_{t}(j) \equiv M_{t}(j)^{\frac{1}{\theta-1}}\left(\int_{0}^{M_{t}(j)} p_{t}(j, i)^{1-\theta} d i\right)^{\frac{1}{1-\theta}}
$$

and the aggregate price index

$$
P_{t} \equiv N_{t}^{\frac{1}{\gamma-1}}\left(\int_{0}^{N_{t}} P_{t}(j)^{1-\gamma} d j\right)^{\frac{1}{1-\gamma}} .
$$

Firms hire labor, $h_{t}(j, i)$, and capital services, $k_{t}(j, i)$, and have access to the production technology

$\int_{0}^{N_{t}(i)} y_{t}(j, i) d j=\int_{0}^{N_{t}(i)}\left[z_{t} k_{t}(j, i)^{\alpha} h_{t}(j, i)^{1-\alpha}-\phi\right] d j-\phi_{f} \quad 0<\alpha<1, \phi>0, \phi_{f}>0$.

Here, $N_{t}(i)$ is the product range of firm $i$ and $z_{t}$ symbolizes total factor productivity that affects all firms equally. The parameter $\phi_{f}$ stands for an overhead cost component that applies in each period of an active firm and it is independent of how much output is produced. The term $\phi$ is specific to each variety that is offered and can be thought of as marketing or development costs. It restricts the amount of varieties offered by firms.

\footnotetext{
${ }^{3}$ Assuming that $\theta>\gamma$ does not affect most of our results, however, it guarantees that the markup is countercyclical.
} 


\subsection{Market structure, product scope choice and symmetric equi- librium}

The decisions of an intermediate good firm follows a two-stage game. In the first stage, firms choose how many varieties to produce. In the second, they compete as Bertrand competitors and choose their markups, labor and capital. The model is solved by backward induction using the subgame Nash perfect equilibrium concept. Free entry via a zero-profit condition determines the number of firms. Since all firms face the same costs, technology and behavior is governed by identical first-order conditions, a symmetric Nash equilibrium emerges every period. Taking logs of (1) yields

$$
\ln y_{t}(j, i)=-\theta \ln p_{t}(j, i)+(\theta-\gamma) \ln P_{t}(j)+\gamma \ln P_{t}+\ln Y_{t}-\ln N_{t}-\ln M_{t}(j)
$$

and since firms take the aggregate price index as given, the price of elasticity of demand is $^{4}$

$$
\frac{\partial \ln y_{t}(j, i)}{\partial \ln p_{t}(j, i)}=-\theta+(\theta-\gamma)\left(\frac{p_{t}(j, i)}{P_{t}(j)}\right)^{1-\theta} M_{t}(j)^{-1}
$$

Since $\partial \ln p_{t}(k, i) / \partial \ln p_{t}(j, i)=0$, it follows that

$$
\partial \ln P_{t}(k) / \partial \ln p_{t}(j, i)=\partial \ln y_{t}(k, i) / \partial \ln p_{t}(j, i)=0 .
$$

Firms maximize profits while taking factor prices $w_{t}$ and $r_{t}$ as given. Optimal factor demands and optimal pricing entail

$$
\begin{gathered}
w_{t}=(1-\alpha) \Lambda_{t} z_{t} k_{t}(j, i)^{\alpha} h_{t}(j, i)^{-\alpha} \\
r_{t}=\alpha \Lambda_{t} z_{t} k_{t}(j, i)^{\alpha-1} h_{t}(j, i)^{1-\alpha}
\end{gathered}
$$

and

$$
y_{t}(j, i)=\left[p_{t}(j, i)-\Lambda_{t}\right]\left(\frac{y_{t}(j, i)}{p_{t}(j, i)} \theta+\frac{y_{t}(j, i)}{p_{t}(j, i)}(\gamma-\theta)\left(\frac{p_{t}(j, i)}{P_{t}(j)}\right)^{1-\theta} M_{t}(j)^{-1}\right)
$$

where $\Lambda_{t}$ are marginal costs. Since all firms face the same factor prices, each will charge the same price for its products. The last equation then rearranges for the markup

$$
\mu_{t}(j, i) \equiv \frac{p_{t}(j, i)}{\Lambda_{t}}=\frac{\theta+(\gamma-\theta)\left(\frac{p_{t}(j, i)}{P_{t}(j)}\right)^{1-\theta} M_{t}(j)^{-1}}{\theta+(\gamma-\theta)\left(\frac{p_{t}(j, i)}{P_{t}(j)}\right)^{1-\theta} M_{t}(j)^{-1}-1}
$$

as for any firm $i$ the price of product $j$ is the same, that is $p_{t}(j, i)=p_{t}(j, k)$. If firm $i$ was the only firm selling product $j$ then $p_{t}(j, i)=P_{t}(j)$ and $\mu_{t}(j, i)=\gamma /(\gamma-1)$. Firm entry into this market will then drive down this markup. It is also clear that if $\theta=\gamma$ then the

\footnotetext{
${ }^{4}$ If firms take $P_{t}(j)$ as given, there is only the first term, and $\partial \ln y_{t}(j, i) / \partial \ln p_{t}(j, i)=-\theta$. The model largely remains unchanged with the only notable difference being a constant markup.
} 
markup is constant at $\theta /(\theta-1)$. Using the above first-order conditions, profits can be written as

$$
\pi_{t}(i)=\int_{0}^{N_{t}(i)} y_{t}(j, i)\left[p_{t}(j, i)-\Lambda_{t}\right] d j-\Lambda_{t}\left[N_{t}(i) \phi+\phi_{f}\right]
$$

To change the product line a firm chooses the length of the $N_{t}$-integral. Firm $i$ takes the number of active firms and their product scope choices as given and then maximizes its own profits with respect to $N_{t}(i)$ while taking into account the effect of its product scope decision on its own and all other producers' pricing decisions. From (1) and noting that if only one firm is producing the new product $p_{t}(N, i) / \Lambda_{t}=\gamma /(\gamma-1)$ and $p_{t}(N, i)=P_{t}(N)$, the first-order condition for the product scope, $\partial \pi_{t}(i) / \partial N_{t}(i)=0$, becomes

$$
\Lambda_{t} \phi=\left(\frac{P_{t}(N)}{P_{t}(j)}\right)^{1-\gamma}\left(\frac{P_{t}(j)}{P_{t}}\right)^{1-\gamma} \frac{P_{t} Y_{t}}{\gamma N_{t}}-\int_{0}^{N_{t}(i)}\left(\frac{p_{t}(j, i)}{P_{t}(j)}\right)^{1-\theta}\left(\frac{P_{t}(j)}{P_{t}}\right)^{1-\gamma} \frac{P_{t} Y_{t}}{\gamma N_{t}} M_{t}(j)^{-1} N_{t}^{-1} d j .
$$

The left-hand side represents the cost of producing a new variety. The first term on the right hand side represents the extra revenue from selling the new variety and the second term the loss of revenue due to the cannibalization effect (new products reducing the demand for existing varieties). This effect not only cannibalizes the demand for firm $i$ 's products but also the demand for other firms' products.

In a symmetric equilibrium, each firm produces the same number of varieties $N_{t}(i)=$ $N_{t}$ and charges the same price $p_{t}$. Let us designate the final good to be the numeraire, $P_{t}=1$, and therefore from (2) and (3), $p_{t}=P_{t}$. The markup simplifies to

$$
\mu_{t}=\frac{\theta M_{t}+\gamma-\theta}{(\theta-1) M_{t}+\gamma-\theta}
$$

and the zero-profit condition governs firm entry

$$
M_{t}=\frac{Y_{t}\left(\mu_{t}-1\right)}{N_{t} \phi+\phi_{f}}
$$

Noting from (4) that $p_{t}(N, i) / \Lambda_{t}=\gamma /(\gamma-1)$ and that $P_{t}(N) / P(j)=1$ (see Appendix A.2), (5) rearranges for the product scope

$$
N_{t}=\frac{Y_{t}}{\phi}\left(\frac{\mu_{t}}{\gamma}-\frac{\mu_{t}-1}{M_{t}}\right)
$$

As will be shown in the next sections, the product scope is procyclical. ${ }^{5}$ Substituting (6) and $Y_{t}=M_{t} N_{t} y_{t}$ in (8) rearranges for output per variety

$$
y_{t}=\frac{\phi \gamma\left(M_{t}(\theta-1)+\gamma-\theta\right)}{\theta M_{t}\left(M_{t}-1\right)}
$$

\footnotetext{
${ }^{5}$ It is also clear that in the case where the number of firms is constant (i.e. the zero profit condition holds at the steady state only), the markup is also constant, and the product scope positively comoves with output.
} 
which, like in Minniti and Turino (2013) and others, is countercyclical with respect to the number of firms due to the cannibalization effect. Finally, denoting aggregate capital and hours as $K_{t}=M_{t} N_{t} k_{t}$ and $H_{t}=M_{t} N_{t} h_{t}$, it is straightforward to obtain aggregate output

$$
Y_{t}=\frac{z_{t} K_{t}^{\alpha} H_{t}^{1-\alpha}}{\mu_{t}}
$$

and factor prices

$$
w_{t}=(1-\alpha) \frac{Y_{t}}{H_{t}} \quad \text { and } \quad r_{t}=\alpha \frac{Y_{t}}{K_{t}}
$$

\subsection{Product scope}

This section shows that multi-product firms exist even when variety effects are assumed away and discusses the calibration of market power parameters $\mu, \theta$, and $\gamma$. This is of importance since Pavlov and Weder (2017) have shown that the intra-firm variety effect in the market segmentation case was necessary in order for firms to produce multiple products. To do this, we press into service (6), (7) and (8) so that the product scope can be written $\mathrm{as}^{6}$

$$
N_{t}=\frac{\phi_{f}}{\phi} \frac{\mu_{t} \theta(\gamma-1)-\gamma \theta}{\mu_{t} \theta+\gamma \mu_{t}-2 \gamma \theta\left(\mu_{t}-1\right)} .
$$

Multi-product firms exist whenever $N_{t}$ is strictly positive and they are inversely related to variety-specific fixed costs $\phi$. Let us begin with the case of firms being single-good sellers, i.e. by normalization $N_{t} \rightarrow 0$. This case is equivalent to

$$
\mu_{t}=\frac{\gamma}{\gamma-1} \equiv \mu^{\max }
$$

Here, the number of firms is at its lower limit and this upper bound of the markup corresponds to the situation of a single good and nest produced in the economy, thus, attaining maximum market power for that firm. The product scope maxes when $\mu_{t}$ is such that

$$
\mu^{\max }>\mu_{t}=\frac{2 \theta \gamma}{2 \theta \gamma-\theta-\gamma} \equiv \mu^{\min }>\frac{\theta}{\theta-1}
$$

in which case $N_{t} \rightarrow \infty$ and the mass of firms reaches its maximum at $M_{t}=(\theta+\gamma) / \theta$. If the number of firms were higher then profits would be negative. In the absence of any cost advantages or the love of variety, the markup would be too low to cover the fixed costs required to maintain the product range (it can be shown that as long as the markup is between $\mu^{\min }$ and $\mu^{\max }$ then profits are sufficient to cover the two fixed costs). As all nests are populated by multiple goods and firms, the markup $\mu^{\text {min }}$ is determined by a combination of the inter-firm and the inter-product elasticities of substitution. It is easily conceived from the expression of $\mu^{\text {min }}$ that the two elasticities operate symmetrically.

\footnotetext{
${ }^{6}$ Note that this equation only holds if the markup is variable, i.e. $\theta \neq \gamma$. If the markup is constant then equation (6) cannot be used to eliminate the number of firms, $M_{t}$.
} 
Also, this markup is strictly smaller than $\mu^{\max }$. Since $\theta>\gamma$, the minimum markup is greater than $\theta /(\theta-1)$ which would prevail in the monopolistic competition version of the model in which firms take the price index $P_{t}(j)$ as given or when $\theta=\gamma$. It is easily demonstrated that the product scope and the markup are inversely related

$$
\frac{\partial N_{t}}{\partial \mu_{t}}=\frac{\phi_{f}}{\phi} \frac{\gamma(\gamma-\theta)}{\left(\mu_{t} \theta+\gamma \mu_{t}-2 \gamma \mu_{t} \theta+2 \gamma \theta\right)^{2}}<0 .
$$

Entry of competitors lowers market power and leads to a higher product scope. Since entry reduces the market share and profits from existing varieties, firms will then have an incentive to produce new goods (i.e. establish new product nests) to command potentially greater market power over them. Since all firms face the same constraints and technologies, they all enter the market for new products and the production of existing varieties then drops (i.e. a cannibalization effect). The outcome of entry is therefore lower output per product nest, $M_{t} y_{t}$, but a higher output per firm, $N_{t} y_{t}$. Finally, (9) and (10) imply that $\gamma$ must satisfy

$$
\frac{\theta \mu}{2 \theta(\mu-1)-\mu}<\gamma<\frac{\mu}{\mu-1} .
$$

\section{The statistical behavior of the model}

This section asks whether the artificial economy's comovements are consistent with the observed behavior of the analogous data series. Let us begin by embedding people to the model.

\subsection{General equilibrium and shocks}

People are represented by an agent with lifetime utility

$$
\sum_{t=0}^{\infty} \beta^{t} u\left(C_{t}, H_{t}\right)
$$

who owns both factors of production and sells their services to the firms. We also introduce variable capital utilization and the agent's intertemporal constraint implies

$$
K_{t+1}=\left(1-\delta_{t}\right) K_{t}+w_{t} H_{t}+r_{t} K_{t}-C_{t}
$$

in which the physical rate of capital depreciation $\delta_{t}=\frac{1}{\kappa} u_{t}^{\kappa}$ is a convex function of the utilization rate $u_{t}$, a rate that is decided by the owner of capital. ${ }^{7}$ Accordingly, each firm $i$ 's production function for product $j$ becomes

$$
z_{t}\left(u_{t} k_{t}(j, i)\right)^{\alpha}\left(g^{t} h_{t}(j, i)\right)^{1-\alpha}-g^{t} \phi
$$

\footnotetext{
${ }^{7}$ The steady state equilibrium conditions dictate that $\kappa=(g / \beta-1+\delta) / \delta$.
} 
where $g$ is the gross growth rate of labor augmenting technological progress that affects all firms equally. We then simulate the artificial economy by unsettling it with sequences of two wedges. While we remain agnostic about the real underlying factors, one may think of them as aggregate supply and demand disturbances but mappings may exist between our model and detailed models with frictions that do not follow this convention. ${ }^{8}$ In the model they enter as perturbations to technology and preferences. Technology shocks are straightforward and are simply the Solow residuals in the production function. Preference shocks disturb the marginal rate of substitution between consumption and leisure. We follow Arseneau and Chugh (2012) and Foroni et al. (2018) in that the shocks act on the disutility of work. ${ }^{9}$ In reduced form, the two shocks parallel the efficiency wedge $z_{t}$ and the labor wedge $\tau_{t}$, and, in line with Brinca et al. (2016), we restrict our analysis to these two wedges since they constitute the main driving forces of fluctuations of the U.S. aggregate economy. Formally, the labor wedge derives from the static first-order condition given agents' period utility function

$$
u\left(C_{t}, H_{t}\right)=\ln C_{t}-\Delta_{t} \frac{v}{1+\chi} H_{t}^{1+\chi} \quad v>0, \chi \geq 0
$$

in which $\Delta_{t}$ is the preference shock, $v$ measures the disutility of working and $\chi=2$ is the Frisch labor supply elasticity. This value aligns with Chetty et al.'s (2013) recommendations for calibrating macroeconomic models. The first-order conditions from the agent's utility maximization problem and the equilibrium real wage combine to

$$
\Delta_{t}=\frac{Y_{t}}{C_{t}} \frac{1-\alpha}{v H_{t}^{1+\chi}}=\frac{1}{1-\tau_{t}}
$$

where the second equality points to the relation with Shimer's (2009) labor wedge. From the aggregate production function, the conventional Solow residual adjusted for utilization, $S R_{t}$, implies

$$
S R_{t}=\hat{Y}_{t}-\alpha \hat{K}_{t}-\alpha \hat{u}_{t}-(1-\alpha) \hat{H}_{t}=\hat{z}_{t}-\hat{\mu}_{t}
$$

where hatted variables denote percent deviations from the steady state. The countercyclical markup gives an upward bias to $S R_{t}$ as an estimator of the efficiency wedge. Using the log-linearized equations, we can eliminate the markup to yield

$$
\hat{z}_{t}=\left(1+\varepsilon_{\mu}\right) \hat{Y}_{t}-\alpha \hat{K}_{t}-\alpha \hat{u}_{t}-(1-\alpha) \hat{H}_{t}
$$

where

$$
\varepsilon_{\mu} \equiv-\frac{\mu \theta+\gamma(\mu+2 \theta-2 \mu \theta)}{\mu(\gamma+\theta-2 \gamma \theta)}<0
$$

\footnotetext{
${ }^{8}$ Brinca et al. (2016) discuss various such mappings.

${ }^{9}$ Baxter and King (1991), Bencivenga (1992) and Weder (2006) imbue some demand side flavor to such preference shocks.
} 
is the markup elasticity with respect to output. We calibrate the steady state markup to $\mu=1.3$, which lies in the proximity of the level estimated by De Loecker et al. (2020), Edmond et al. (2019) and others. The elasticity of substitution between products within a nest is $\theta=10$, which is close to the midpoint between the two elasticities estimated by Broda and Weinstein (2010). Given (11) and the above calibration, the inter-product elasticity $\gamma$ must lie between 2.77 and 4.33 . We set $\gamma=3.5$, which is approximately halfway between these bounds. Finally, to make comparisons with previous studies straightforward: $\alpha=0.3, \delta=0.025$ and $\beta=0.99$. The above is then used to estimate $z_{t}$ from observable data. The correlation between the HP filtered efficiency wedge and Fernald's (2014) utilization adjusted counterpart over the entire sample is 0.70 .

Using U.S. data ranging from 1948:II to 2019:IV, we find that the two wedges appear to undergo several changes in regards to their cyclical pattern. When reporting is based on Hodrick-Prescott filtered time series with $\lambda=1600$, the efficiency wedge's standard deviation drops slightly when comparing pre- and post 1983 periods (1983:IV is the cut-off quarter, coinciding with the onset of the Great Moderation). Also, the efficiency wedge's contemporaneous correlation with output goes from 0.22 to -0.29 for the second period. As this wedge is simply a more agnostic measure of total factor productivity, its decline points to a smaller importance of supply shock factors. In fact, it parallels the trend in U.S. labor productivity to labor correlation which became strongly countercyclical, from -0.30 to -0.82 . The labor wedge does not go through such shifting pattern as its output correlation remains constant at -0.83 . This wedge's standard deviation increases by 31 percent which suggests that shocks that affect the labor wedge have become more important relative to the efficiency wedge. Both wedges are highly persistent which translates to our calibration of parameters $\rho_{z}=0.970$ and $\rho_{\Delta}=0.985$ and by restricting the driving processes to $\mathrm{AR}(1)$, for example, the labor supply shock follows ${ }^{10}$

$$
\ln \Delta_{t}=0.985 \ln \Delta_{t-1}+(1-0.985) \ln \Delta+\varepsilon_{t}^{\Delta} .
$$

\subsection{Aggregate fluctuations}

To assess aggregate fluctuations as seen through the lens of our model, we feed back in the sequence of shocks $\left\{\varepsilon_{t}^{z}, \varepsilon_{t}^{\Delta}\right\}_{1948: I I}^{2019: I V}$ into the log-linearized artificial economy. Table 1 reports data and artificial second moments for the pre-Great Moderation as well as for post-1983 periods. Again, everything has been Hodrick-Prescott filtered and in terms of the key aggregates the model replicates well the relative standard deviations as well as the moderation of volatilities across the two subperiods. The model also predicts a fall in the volatility of utilization. Labor productivity has remained basically unchanged.

\footnotetext{
${ }^{10} \mathrm{We}$ also considered allowing for crosscorrelated wedges but decided to keep our presentation parsimonious.
} 
The model correctly mimics this pattern. As in Arias et al. (2007), the post-1983 decline in business cycle volatility comes about from a lower volatility of shocks - the standard deviations of efficiency and labor wedge shocks decrease by 33 and 26 percent. However, the composition of shocks - the labor wedge shocks become more important - plays a key role as you will see next. ${ }^{11}$

\begin{tabular}{|l|c|l|l|l|}
\hline Table 1: Standard deviations \\
\hline & \multicolumn{2}{|c|}{$1948-1983$} & \multicolumn{2}{c|}{$1984-2019$} \\
\hline & U.S. & Model & U.S. & Model \\
\hline Output & 2.02 & 1.94 & 1.01 & 1.06 \\
\hline Consumption & 0.95 & 0.95 & 0.70 & 0.55 \\
\hline Investment & 5.21 & 5.53 & 4.28 & 2.98 \\
\hline Hours & 2.10 & 2.01 & 1.62 & 1.61 \\
\hline Utilization & 1.76 & 1.22 & 0.98 & 0.70 \\
\hline Labor productivity & 0.91 & 0.99 & 0.93 & 1.01 \\
\hline
\end{tabular}

Table 2 and 3 lay out cross-correlations for data (upper diagonal) and model (lower diagonal). In addition to matching correlations across the board, two features jump out. The model not only solves Christiano and Eichenbaum's (1992) hours-productivity puzzle but also replicates the increasingly more negative correlation that you can observe for the post-1983 data (from -0.30 to -0.82 ). Also, the correlation of labor productivity and output in the model drops from 0.18 to -0.22 which parallels the fall of 0.14 to -0.40 in the data. This fall lines up with the findings of, for example, Galí and Gambetti (2009), Hagedorn and Manovskii (2011) and Galí and van Rens (2019) regarding a changed cyclicality of labor productivity. Similar to Barnichon (2010) and Garin et al. (2018), our work speculates that this change reflects shifts to the composition of the wedges. The intuition can be framed in the spot labor market of the model. The efficiency wedge knocks around the labor demand curve and the labor wedge shocks the labor supply curve. If fluctuations of the labor wedges become more prevalent then labor productivity becomes less procyclical as the driver of this procyclicality grows less important. The same shift to the shock composition turns the correlation of productivity and hours to more negative precincts.

\begin{tabular}{|l|l|l|l|l|l|l|}
\multicolumn{6}{|c|}{ Table 2: 1948 -1983 cross correlations } \\
\hline & $Y$ & $C$ & $X$ & $H$ & $\frac{Y}{H}$ & $U$ \\
\hline$Y$ & 1 & 0.76 & 0.78 & 0.90 & 0.14 & 0.84 \\
\hline$C$ & 0.97 & 1 & 0.60 & 0.75 & -0.02 & 0.59 \\
\hline$X$ & 0.99 & 0.93 & 1 & 0.77 & -0.05 & 0.71 \\
\hline$H$ & 0.87 & 0.93 & 0.82 & 1 & -0.30 & 0.75 \\
\hline$\frac{Y}{H}$ & 0.18 & 0.01 & 0.34 & -0.32 & 1 & 0.14 \\
\hline$U$ & 0.97 & 0.89 & 0.99 & 0.81 & 0.24 & 1 \\
\hline
\end{tabular}

\footnotetext{
${ }^{11}$ This might appear to be at odds with Galí and Gambetti (2009) but the wedges do not map directly into their concepts of nontechnology and technology shocks. A further reason might be related to the additional 15 years we cover here that, of course, include the Great Recession which Brinca et al. (2016) coin a labor wedge recession.
} 


\begin{tabular}{|l|l|l|l|l|l|l|}
\hline \multicolumn{7}{|c|}{ Table 3: 1984 -2019 cross correlations } \\
\hline & $Y$ & $C$ & $X$ & $H$ & $\frac{Y}{H}$ & $U$ \\
\hline$Y$ & 1 & 0.80 & 0.87 & 0.85 & -0.40 & 0.71 \\
\hline$C$ & 0.95 & 1 & 0.65 & 0.69 & -0.34 & 0.51 \\
\hline$X$ & 0.98 & 0.87 & 1 & 0.90 & -0.63 & 0.68 \\
\hline$H$ & 0.79 & 0.91 & 0.68 & 1 & -0.82 & 0.63 \\
\hline$\frac{Y}{H}$ & -0.22 & -0.45 & -0.06 & -0.77 & 1 & -0.33 \\
\hline$U$ & 0.97 & 0.86 & 0.99 & 0.73 & -0.16 & 1 \\
\hline
\end{tabular}

Table 4 confirms that the model fits the data well by presenting the correlations between the artificial and U.S. series. In particular, output, hours and labor productivity are almost perfectly correlated. This finding, in combination with the model's ability to fluctuate nearly the same amplitude as the U.S. economy, suggests that indeed the two shocks, i.e. labor and efficiency, explain the bulk of U.S. aggregate fluctuations.

\begin{tabular}{|l|l|l|l|l|l|l|}
\hline Table 4: Data vs Model correlations \\
\hline & $Y$ & $C$ & $X$ & $H$ & $\frac{Y}{H}$ & $U$ \\
\hline $1948-1983$ & 0.96 & 0.85 & 0.71 & 0.99 & 0.92 & 0.74 \\
\hline $1984-2019$ & 0.95 & 0.87 & 0.72 & 0.99 & 0.98 & 0.58 \\
\hline
\end{tabular}

\subsection{Product scope, firm dynamics and markup fluctuations}

Central to our model is the role of the time-varying product scope, firm net entry and markups. ${ }^{12}$ Regarding the procyclicality of the entry rate, evidence abounds (e.g. Lee and Mukoyama, 2018). There is a long list of research suggesting a countercyclical markup and Bils et al. (2018) is one representative. ${ }^{13}$ Guo (2020) presents evidence for a procyclical product scope pattern by applying Nielsen Retail Scanner data of U.S. consumer goods purchases. In the spirit of her paper, we ran regressions of the product scope and two measures of aggregate business cycle activity. In particular, we take time series from our artificial economy model when simulated using actual preferences and technology shocks from the 2007:I to 2014:IV period, which matches Guo's, and find that growth rates (product scope, consumption and utilization) have the following relationships:

$$
\begin{array}{ll}
\Delta \ln N_{t}=\underset{(4.58)}{0.004}+\underset{-(19.01)}{3.532} \Delta \ln C_{t} & \bar{R}^{2}=0.91 \\
\Delta \ln N_{t}=\underset{(-13.83)}{0.005}+\underset{(35.55)}{2.298 \Delta \ln U_{t}} & \bar{R}^{2}=0.97
\end{array}
$$

where t-values are in parentheses. Clearly, the coefficients are not directly comparable to Guo's (2020) since she places firms into different categories, however, our model produces a procyclical pattern similar to her empirical findings. ${ }^{14}$ Table 5 presents the Hodrick and

\footnotetext{
${ }^{12}$ See Bilbiie et al. (2019) or Colciago and Etro (2010) for discussions of product variety dynamics in mono-product firms cases.

${ }^{13}$ Nekarda and Ramey (2020) counter this apparent consensus.

${ }^{14}$ We also ran a regression using the level of utilization rates
}

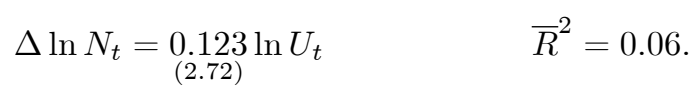


Prescott filtered standard deviations for the product scope, the number of firms, and the markup for the 1948-1983 and 1984-2019 periods. Here, and once again, all series have become less volatile after 1983. Net firm entry and product scope are strongly procyclical and the markup moves countercyclically. The product scope is approximately one and a half times more volatile than output and the volatility of firms is only one tenth. The low volatility of the number of firms implies a relatively smooth countercyclical markup that acts as a mild amplification mechanism. ${ }^{15}$

\begin{tabular}{|l|l|l|l|l|}
\hline \multicolumn{4}{|c|}{ Table 5: Firm dynamics and markups } \\
\hline & $1948-1983$ & \multicolumn{2}{l|}{$1984-2019$} \\
\hline Variable, $x$ & $\sigma_{x}$ & $\rho(x, Y)$ & $\sigma_{x}$ & $\rho(x, Y)$ \\
\hline$N$ & 3.12 & 1.00 & 1.71 & 1.00 \\
\hline$M$ & 0.23 & 1.00 & 0.13 & 1.00 \\
\hline$\mu$ & 0.09 & -1.00 & 0.05 & -1.00 \\
\hline
\end{tabular}

\subsection{A Burns-Mitchell analysis}

We end by calling into play a classical method of business cycle analysis developed by Burns and Mitchell (1946) and Adelman and Adelman (1959) that evaluates theory in terms of whether it mimics the cyclical behavior of post-war U.S. data. ${ }^{16}$ A brief description of their idea follows. The business cycle series consist of a sequence of reference cycles, measured trough-to-trough by convention. We use NBER dates to determine the peak of the reference cycle for both U.S. and artificially generated data. Our preGreat Moderation series includes seven complete trough-peak-trough cycles beginning in 1949:IV and ending in 1982:IV. The Great Moderation series includes three cycles ending in 2009:II. Each complete reference cycle is divided into nine stages (I to IX). Stage I is the initial trough, stage $\mathrm{V}$ is the reference peak, and stage IX is the terminal trough. The expansion phase (stages I to V) is divided into three substages (II, III, and IV) of equal length (excluding time contained in stages I and V). The contraction phase (stages $\mathrm{V}$ to IX) is measured in an analogous fashion. Next, each observation in the cycle is expressed as a percentage of the cycle mean called cycle relatives. Mean cycle relatives per stage are averaged across all reference cycles to yield a graphical summary of an average business cycle in the nine-point-plot of Figure 1. The plot provides a visual impression of both the simulated data and the U.S. data (if available). Concretely, Figure 1 displays the average behavior, in cycle relatives, over the nine stages of the business cycle for per capita real GDP and the artificial equivalent when the model is driven by both shocks. Stage I coincides with the initial trough, stage V with the peak, and stage IX corresponds to the terminal trough. The similar general shape of the two series demonstrates that the

\footnotetext{
${ }^{15}$ Increasing $\gamma$ leads to a higher markup elasticity, $\varepsilon_{\mu}$, and to a greater volatility in $N$ and $M$. Apart from this, the results are robust to different values of $\gamma$.

${ }^{16}$ See also Simkins (1994) and King and Plosser (1994).
} 

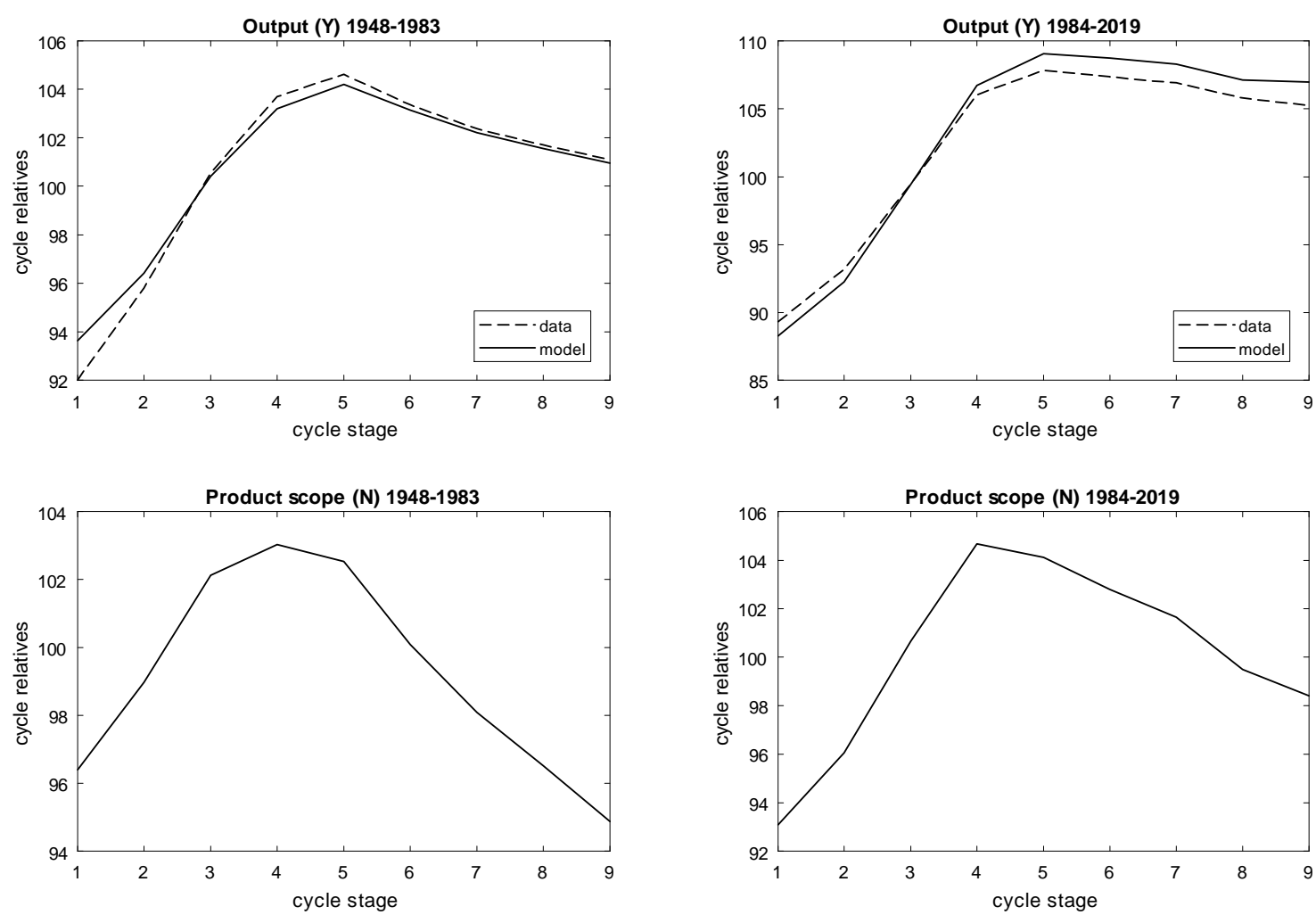

Figure 1: Average behavior of aggregate output and product scope.

artificial series matches well the post-war U.S. cycles. The per capita real GDP exhibits a distinct procyclical pattern, rising during expansions and falling during contractions. Both series peak at the same stage. Analogous to Table 5, the product scope is clearly procyclical and it follows a similar pattern as aggregate economic activity. ${ }^{17}$

\section{Conclusion}

This paper examines multi-product firm dynamics taking a market interlacing industry configuration to general equilibrium. In contrast to previous studies that frame multiproduct firms in a market segmentation setup, we show within a market interlacing platform that firms produce multiple products even in the complete absence of the love of variety effects. The model implies a procyclical product scope which agrees with Guo's $(2019,2020)$ empirical findings. In addition, entry and exit of firms provide an endogenous amplification mechanism. When simulated by shocks derived from empirical efficiency and labor wedges, the model predicts procyclical product scopes and net firm entry. The simulated model replicates the changes in dynamics between the pre-Great Moderation era and the post-1983 period as well as explains the labor-productivity puzzle.

\footnotetext{
${ }^{17}$ As we do not have aggregate data counterparts, we only display the artificial responses.
} 


\section{References}

[1] Adelman F. and I. Adelman (1959): "The Dynamic Properties of the KleinGoldberger Model", Econometrica 27, 596-625.

[2] Allanson, P. and C. Montagna (2005): "Multiproduct Firms and Market Structure: An Explorative Application to the Product Life Cycle", International Journal of Industrial Organization 23, 587-597.

[3] Arias, A., G. Hansen and L. Ohanian (2007): "Why Have Business Cycle Fluctuations Become Less Volatile?", Economic Theory 32, 43-58.

[4] Arseneau, D. and S. Chugh (2012): "Tax Smoothing in Frictional Labor Markets", Journal of Political Economy 120, 926-985.

[5] Bailey, E. and A. Friedlaender (1982): "Market Structure and Multiproduct Industries", Journal of Economic Literature 20, 1024-1048.

[6] Barnichon, R. (2010): "Productivity and Unemployment over the Business Cycle", Journal of Monetary Economics 57, 1013-1025.

[7] Baxter, M. and R. King (1991): "Productive Externalities and Business Cycles", Federal Reserve Bank of Minneapolis, mimeo.

[8] Bencivenga, V. (1992): "An Econometric Study of Hours and Output Variation with Preference Shocks", International Economic Review 33, 449-471.

[9] Bernard, A., S. Redding and P. Schott (2010): "Multi-Product Firms and Product Switching", American Economic Review 100, 70-97.

[10] Bilbiie, F., F. Ghironi, and M. Melitz (2019): "Monopoly Power and Endogenous Product Variety: Distortions and Remedies", American Economic Journal: Macroeconomics 11, 140-174.

[11] Bils, M., P. Klenow and B. Malin (2018): "Resurrecting the Role of the Product Market Wedge in Recessions", American Economic Review 108, 1118-1146.

[12] Brander J. and J. Eaton (1984): "Product Line Rivalry", American Economic Review $74,323-334$.

[13] Brinca, P., V.V. Chari, P. Kehoe and E. McGrattan (2016): "Accounting for Business Cycles", in: John Taylor and Harald Uhlig (editors), Handbook of Macroeconomics 2, Elsevier, 1013-1063.

[14] Broda, C., and D. Weinstein (2010): "Product Creation and Destruction: Evidence and Price Implications", American Economic Review 100, 691-732. 
[15] Burns A. and W. Mitchell (1946): Measuring Business Cycles, NBER Books, New York.

[16] Chetty, R., A. Guren, D. Manoli, and A. Weber (2013): "Does Indivisible Labor Explain the Difference between Micro and Macro Elasticities? A Meta-Analysis of Extensive Margin Elasticities", NBER Macroeconomics Annual 2012, University of Chicago Press, 1-56.

[17] Christiano, L. and M. Eichenbaum (1992): "Current Real-Business-Cycle Theories and Aggregate Labor-Market Fluctuations", American Economic Review 82, 430450.

[18] Colciago, A. and F. Etro (2010): "Endogenous Market Structures and the Business Cycle", Economic Journal 120, 1201-1233.

[19] De Loecker, J., J. Eeckhout and G. Unger (2020): "The Rise of Market Power and the Macroeconomic Implications", Quarterly Journal of Economics 135, 561-644.

[20] Dixit, A. and J. Stiglitz (1977): "Monopolistic Competition and Optimum Product Diversity", American Economic Review 67, 297-308.

[21] Dunlop, J. (1938): "The Movement of Real and Money Wage Rates", Economic Journal, 48, 413-434.

[22] Edmond, C., V. Midrigan and D. Xu (2019): "How Costly are Markups?", University of Melbourne, mimeo.

[23] Feenstra, R. and H. Ma (2009): "Optimal Choice of Product Scope for Multiproduct Firms under Monopolistic Competition", in Helpman, E., Marin, D., Verdier, T., (editors): The Organization of Firms in a Global Economy, Harvard University Press, Cambridge, 173-199.

[24] Fernald, J. (2014): "A Quarterly, Utilization-Adjusted Series on Total Factor Productivity", Federal Reserve Bank of San Francisco, mimeo.

[25] Foroni, C., F. Furlanetto and A. Lepetit (2018): "Labor Supply Factors And Economic Fluctuations", International Economic Review 59, 1491-1510.

[26] Galí, J. and L. Gambetti (2009): "On the Sources of the Great Moderation", American Economic Journal: Macroeconomics 1, 26-57.

[27] Galí, J. and T. van Rens (2019): "The Vanishing Procyclicality of Labor Productivity", Economic Journal, forthcoming. 
[28] Garin, J., M. Pries and E. Sims (2018): "The Relative Importance of Aggregate and Sectoral Shocks and the Changing Nature of Economic Fluctuations", American Economic Journal: Macroeconomics 10, 119-148.

[29] Guo, D. (2019): "Multiproduct Firms and the Business Cycle", Xiamen University, mimeo.

[30] Guo, D. (2020): "Firm Product Scope, Oligopolistic Competition, and the Business Cycle: Evidence and Theory", Xiamen University, mimeo.

[31] Hagedorn, M. and I. Manovskii (2011): "Productivity and the Labor Market: CoMovement over the Business Cycle", International Economic Review 52, 603-619.

[32] King, R. and C. Plosser (1994): "Real Business Cycles and the Test of the Adelmans", Journal of Monetary Economics 33, 405-438.

[33] Lee, Y. and T. Mukoyama (2018): "A Model of Entry, Exit, and Plant-level Dynamics over the Business Cycle", Journal of Economic Dynamics and Control 96, 1-25.

[34] Minniti, A. and F. Turino (2013): "Multi-product Firms and Business Cycle Dynamics", European Economic Review 57, 75-97.

[35] Nekarda, C. and V. Ramey (2020): "The Cyclical Behavior of the Price-Cost Markup", Journal of Money, Credit and Banking, in press.

[36] Pavlov, O. and M. Weder (2017): "Product Scope and Endogenous Fluctuations", Review of Economic Dynamics 24, 175-191.

[37] Simkins, S. (1994): "Do Real Business Cycle Models Really Exhibit Business Cycle Behavior?", Journal of Monetary Economics 33, 381-404.

[38] Shimer, R. (2009): "Convergence in Macroeconomics: The Labor Wedge", American Economic Journal: Macroeconomics 1, 280-97.

[39] Tarshis, L. (1939): "Changes in Real and Money Wages", Economic Journal 49, 150-154.

[40] Weder, M. (2006): "The Role of Preference Shocks and Capital Utilization in the Great Depression", International Economic Review 47, 1247-1268.

[41] Yang, X. and B. Heijdra (1993): "Monopolistic Competition and Optimum Product Diversity: Comment", American Economic Review 83, 295-301. 


\section{A Appendix}

This Appendix details the source and construction of the U.S. data used in Section 3 as well as various model derivations in more detail.

\section{A.1 Data}

All data is quarterly and for the period 1948:I-2019:IV.

1. Gross Domestic Product. Seasonally adjusted at annual rates, billions of chained (2009) dollars. Source: Bureau of Economic Analysis, NIPA Table 1.1.6.

2. Gross Domestic Product. Seasonally adjusted at annual rates, billions of dollars. Source: Bureau of Economic Analysis, NIPA Table 1.1.5.

3. Personal Consumption Expenditures, Nondurable Goods. Seasonally adjusted at annual rates, billions of dollars. Source: Bureau of Economic Analysis, NIPA Table 1.1.5.

4. Personal Consumption Expenditures, Services. Seasonally adjusted at annual rates, billions of dollars. Source: Bureau of Economic Analysis, NIPA Table 1.1.5.

5. Gross Private Domestic Investment, Fixed Investment, Residential. Seasonally adjusted at annual rates, billions of dollars. Source: Bureau of Economic Analysis, NIPA Table 1.1.5.

6. Gross Private Domestic Investment, Fixed Investment, Nonresidential. Seasonally adjusted at annual rates, billions of dollars. Source: Bureau of Economic Analysis, NIPA Table 1.1.5.

7. Nonfarm Business Hours. Index 2009=100, seasonally adjusted. Source: Bureau of Labor Statistics, Series Id: PRS85006033.

8. Civilian Noninstitutional Population. 16 years and over, thousands. Source: Bureau of Labor Statistics, Series Id: LNU00000000Q.

9. GDP Deflator $=(2) /(1)$.

10. Real Per Capita Output, $Y_{t}=(1) /(8)$.

11. Real Per Capita Consumption, $C_{t}=[(3)+(4)] /(9) /(8)$.

12. Real Per Capita Investment, $X_{t}=[(5)+(6)] /(9) /(8)$.

13. Per Capita Hours Worked, $H_{t}=(9) /(8)$.

14. Capital Utilization, $U_{t}$. "A Quarterly, Utilization-Adjusted Series on Total Factor Productivity", retrieved from http://www.frbsf.org/economic-research/economists/johnfernald/.

\section{A.2 Relative price $P(N) / P(j)$}

This Appendix shows that $P(N) / P(j)=1$. First, define the market share of product $j$ as

$$
Q_{t}(j) \equiv \frac{P_{t}(j) Y_{t}(j)}{P_{t} Y_{t}}=\left(\frac{P_{t}(j)}{P_{t}}\right)^{1-\gamma} N_{t}^{-1}
$$


which is equal to $1 / N_{t}$ in symmetric equilibrium. Market shares sum to unity

$$
\int_{0}^{N_{t}} Q_{t}(j) d j=1
$$

and

$$
\int_{0}^{N_{t}} \frac{\partial Q_{t}(j)}{\partial N_{t}(i)} d j+Q_{t}(N)=0
$$

where $Q(N)$ is the market share of a new product $N$. Taking note that $\frac{\partial p_{t}(j, i)}{\partial N_{t}(i)}=\frac{\partial p_{t}(j, k)}{\partial N_{t}(i)}=$ $\frac{\partial P_{t}(j)}{\partial N_{t}(i)}=0$ (see Appendix A.3), the derivative with respect to the product scope is

$$
\frac{\partial Q_{t}(j)}{\partial N_{t}(i)}=-\frac{Q_{t}(j)}{N_{t}}
$$

Under symmetry

$$
\begin{aligned}
N_{t} \frac{\partial Q_{t}(j)}{\partial N_{t}(i)}+Q_{t}(N) & =0 \\
-Q_{t}(j)+Q_{t}(N) & =0 .
\end{aligned}
$$

Finally, using (A.1) with the above gives

$$
\left(\frac{P_{t}(N)}{P(j)}\right)^{1-\gamma}=1
$$

\section{A.3 The effect of product scope on prices}

This Appendix shows that in symmetric equilibrium, the product scope has no effect on prices. That is, $\frac{\partial p_{t}(j, i)}{\partial N_{t}(i)}=\frac{\partial P_{t}(j)}{\partial N_{t}(i)}=0$. From $(2)$

$$
\frac{\partial P_{t}(j)}{\partial N_{t}(i)}=P_{t}(j)\left(\int_{0}^{M_{t}} p_{t}(j, k)^{1-\theta} d k\right)^{-1} \int_{0}^{M_{t}} p_{t}(j, k)^{-\theta} \frac{\partial p_{t}(j, k)}{\partial N_{t}(i)} d k .
$$

Note from (4), each firm charges the same price for the same product, $p_{t}(j, k)=p_{t}(j, i)$, and hence $\frac{\partial p_{t}(j, k)}{\partial N_{t}(i)}=\frac{\partial p_{t}(j, i)}{\partial N_{t}(i)}$. Therefore (A.2) simplifies to

$$
\frac{\partial P_{t}(j)}{\partial N_{t}(i)}=\frac{P_{t}(j)}{p_{t}(j, i)} \frac{\partial p_{t}(j, i)}{\partial N_{t}(i)} .
$$

From (4)

$$
\begin{aligned}
\frac{\partial p_{t}(j, i)}{\partial N_{t}(i)} \frac{1}{\Lambda_{t}}= & {\left[1-\mu_{t}(j, i)\right] \frac{(1-\theta)(\gamma-\theta)\left(\frac{p_{t}(j, i)}{P_{t}(j)}\right)^{1-\theta} M_{t}^{-1} p_{t}(j, i)^{-1} \frac{\partial p_{t}(j, i)}{\partial N_{t}(i)}}{\theta+(\gamma-\theta)\left(\frac{p_{t}(j, i)}{P_{t}(j)}\right)^{1-\theta} M_{t}^{-1}-1} } \\
& -\left[1-\mu_{t}(j, i)\right] \frac{(1-\theta)(\gamma-\theta)\left(\frac{p_{t}(j, i)}{P_{t}(j)}\right)^{1-\theta} M_{t}^{-1} P_{t}(j)^{-1} \frac{\partial P_{t}(j)}{\partial N_{t}(i)}}{\theta+(\gamma-\theta)\left(\frac{p_{t}(j, i)}{P_{t}(j)}\right)^{1-\theta} M_{t}^{-1}-1}
\end{aligned}
$$

Finally, substituting (A.3) into the above yields $\frac{\partial p_{t}(j, i)}{\partial N_{t}(i)}=0$. 


\section{B Supplementary Appendix (not intended for pub- lication unless requested)}

This Appendix demonstrates the importance of love of variety for the market segmentation setup.

\section{B.1 Why does the variety effect matter?}

Feenstra and Ma (2009), Minniti and Turino (2013) and Pavlov and Weder (2017) introduce multi-product firms into a general equilibrium framework. All three follow Brander and Eaton's (1984) market segmentation setup in which each nest of goods corresponds to a multi-product firm's output of close substitutes. The following shows that without love of variety all firms produce no more than a single product. ${ }^{18}$

Suppose final output, $Y_{t}$, is produced under perfect competition using the range of intermediate inputs supplied by $M_{t}$ multi-product firms indexed $i$. Each firm supplies $N_{t}(i)$ varieties of goods. Accordingly, the final good is constructed via two nested CES aggregators. The first encompasses the varieties from an individual firm $i$ that, when put together, compose

$$
Y_{t}(i)=N_{t}(i)^{1+\tau}\left(\frac{1}{N_{t}(i)} \int_{0}^{N_{t}(i)} y_{t}(i, j)^{\frac{\gamma-1}{\gamma} d j}\right)^{\frac{\gamma}{\gamma-1}} \quad \tau>0, \gamma>1
$$

The parameters $\tau$ stands for the intra-firm variety effect. The firm-composite goods are then stacked together to yield the final output

$$
Y_{t}=M_{t}^{1+\omega}\left(\frac{1}{M_{t}} \int_{0}^{M_{t}} Y_{t}(i)^{\frac{\theta-1}{\theta}} d i\right)^{\frac{\theta}{\theta-1}} \quad \omega \geq 0, \theta>1
$$

where $\omega$ is the inter-firm variety effect. Variety effects are separated from the elasticity of substitution as there is no a priori reason for a strong link between them. The presence of variety effects $\tau$ and $\omega$ imply that there are increasing returns in the aggregation of products. Final output can be produced more efficiently when there are more intermediate good varieties and in symmetric equilibrium

$$
Y_{t}=N_{t}^{1+\tau} M_{t}^{1+\omega} y_{t}
$$

While $\omega$ can be eliminated, as will be shown below, $\tau>0$ is necessary for firms to produce multiple products. It alone provides the gain to product creation that offsets the fixed costs paid to maintain multiple varieties. Profit maximization problem yields

$$
y_{t}(i, j)=\left(\frac{P_{t}(i)}{P_{t}}\right)^{-\theta}\left(\frac{p_{t}(i, j)}{P_{t}(i)}\right)^{-\gamma} M_{t}^{\omega(\theta-1)-1} N_{t}(i)^{\tau(\gamma-1)-1} Y_{t} .
$$

\footnotetext{
${ }^{18}$ Pavlov and Weder (2017) contains more detail.
} 
Intermediate goods are produced using capital, $k_{t}(i, j)$, and labor, $h_{t}(i, j)$, that are supplied on perfectly competitive factor markets. The production technology consists of a constant returns Cobb-Douglas part and involves two fixed costs. The variety-level fixed cost, $\phi$, applies once a variety is added to the production line. The firm-level fixed cost, $\phi_{f}$, provides economies of scope. A firm's output is given by

$$
\int_{0}^{N_{t}(i)} y_{t}(i, j) d j=\int_{0}^{N_{t}(i)}\left[k_{t}(i, j)^{\alpha} h_{t}(i, j)^{1-\alpha}-\phi\right] d j-\phi_{f} \quad \phi>0, \phi_{f}>0 .
$$

Each firm sets prices to maximizes profits

$$
\pi_{t}(i)=\int_{0}^{N_{t}(i)} p_{t}(i, j) y_{t}(i, j)-w_{t} h_{t}(i, j)-r_{t} k_{t}(i, j) d j
$$

where $w_{t}$ and $r_{t}$ are the labor and capital rental rates. Following Yang and Heijdra (1993), intermediate good firms are large enough to take the aggregate price index into consideration when making their pricing decision. Firms charge the same price, $p_{t}(i)$, for all of their varieties and the optimal markup becomes

$$
\mu_{t}(i) \equiv \frac{p_{t}(i)}{m c_{t}}=\frac{\theta\left[1-\epsilon_{t}(i)\right]}{\theta\left[1-\epsilon_{t}(i)\right]-1}
$$

where $m c_{t}$ is the marginal cost of producing an additional variety, and $\epsilon_{t}(i)$ is firm $i$ 's market share:

$$
\epsilon_{t}(i) \equiv \frac{P_{t}(i) Y_{t}(i)}{P_{t} Y_{t}}=\frac{N_{t}(i)^{-\tau(1-\theta)} p_{t}(i)^{1-\theta}}{\int_{0}^{M_{t}} N_{t}(i)^{-\tau(1-\theta)} p_{t}(i)^{1-\theta} d i} .
$$

This highlights the importance of the intra-firm variety effect, $\tau$. Without it, the market share would not depend on the product scope. Profits would be decreasing in $N_{t}(i)$ because of the variety-level fixed cost $\phi$ and hence, firms would only produce a single product. Firms determine their optimal number of products by maximizing profits with respect to $N_{t}(i)$ by taking into account the effect on its own and other firms' pricing decisions and the relevant first-order condition is

$$
\theta P_{t} Y_{t}\left(\frac{p_{t}(i)-m c_{t}}{p_{t}(i)}\right)^{2} \frac{\partial \epsilon_{t}(i)}{\partial N_{t}(i)}+Y_{t} \epsilon_{t}(i)\left(\frac{p_{t}(i)-m c_{t}}{p_{t}(i)}\right) \frac{\partial P_{t}}{\partial N_{t}(i)}=m c_{t} \phi .
$$

The first term on the left-hand side corresponds to the presence of the intra-firm variety effect: introducing a new product increases the firm's market share and its profits. The second term stands for the impact of product scope on the aggregate price index. Specifically, a higher product scope reduces the aggregate price index, $\partial P_{t} / \partial N_{t}(i)<0$, which from (B.1) leads to a lower demand for firm $i$ 's products. The right-hand side represents the cost of producing one additional variety. In the symmetric equilibrium, each firm produces the same number of varieties, $N_{t}(i)=N_{t}$, charges the same price, $p_{t}(i)=p_{t}$, and has the same market share $\epsilon_{t}(i)=1 / M_{t}$. A key equation yields the product scope

$$
N_{t}=\frac{\tau P_{t} Y_{t}}{\phi p_{t} M_{t}}\left[\frac{(\theta-1)\left(M_{t}-1\right) M_{t}}{\theta\left(1-M_{t}\right)+M_{t}^{2}(\theta-1)}+\frac{M_{t}}{M_{t}\left[M_{t}(1-\theta)+\theta\right]}\right] .
$$


In words, firms are single goods producers unless $\tau>0$.

Finally, countercyclical markups are important as they generate procyclical product scopes when entry is determined by the zero profit condition. As firms enter to exhaust profit opportunities, falling market shares reduce markups. Lower markups increase production within firms and they respond by expanding their product scopes. If instead each firm is small relative to the market as in monopolistic competition where $\mu=\theta /(\theta-$ 1), entry has a negligible impact on market shares and existing firms keep their production levels and product scopes constant. The increase in aggregate output is then solely due to the entry of new firms. In (B.2), this corresponds to a large number of firms where the term in square brackets is equal to unity. The number of firms moves proportionally to final output and the product scope is constant. In contrast, countercyclical markups in the market interlacing configuration are not required for the product scope to be variable. Constant markups in (8) still produce procyclical product scopes. Here, profit opportunities give each firm an incentive to produce the next variety in the $N$ product line that no other firm is currently producing. Since all firms are identical, all end up producing the new product and profits are driven down to zero due to the fixed costs that are paid to maintain the new product. The extra cost of producing new varieties exhausts profits and deters entrants, leading to a relative smooth movement in the number of firms as shown in Table 5. 